\title{
A web-based Decision Support System (DSS) to assist Small and Medium-sized Enterprises (SMEs) to broker risks and rewards for BIM adoption
}

\author{
T. T. Lam, L. Mahdjoubi \& J. Mason \\ Department of Architecture and Built Environment, \\ The University of the West of England, UK
}

\begin{abstract}
Building Information Modelling (BIM) is a revolutionary technology and process which has led to new ways of thinking and working in construction project delivery. Governments around the world are promoting BIM capacity to eliminate waste on public projects and even mandating its use as part of the reform of the public construction sector and cost-saving strategy. In the UK, the government has declared that no public projects can be accepted without using BIM by 2016 . Evidence shows that BIM adoption among small and medium sized enterprises (SMEs) is currently lagging behind and they are losing out in wining publicly funded projects. There are existing sets of frameworks and matrixes developed to assist BIM implementation. However, guidance and frameworks for SMEs are lacking at the present time. This paper reports on criteria and framework as a part of an ongoing study that seeks to develop a web-based Decision Support System (DSS) to assist SMEs to broker risks and rewards of adopting BIM in project delivery. The paper presents the framework and its criteria of the proposed DSS assists SMEs to make informed decisions about whether or not use BIM to deliver building projects, according to specific criteria and queries. This includes tradeoff risks and rewards, broken down into several criteria such as BIM readiness, involvement stage, project value, funding and procurement route.

Keywords: BIM, risk, reward, client, SMEs, opportunity.
\end{abstract}




\section{Introduction}

Building Information Modelling (BIM) has recently attained widespread attention and is considered one of the most fertile areas for new ideas in terms of the development of Architecture, Engineering and Construction (AEC). BIM was described by the SEC Group [1] as "a way of working", where stakeholders can use BIM digital model to share information and knowledge, collaboratively harness the talents and insights of all participants to reduce waste and optimise efficiency thorough all phrases of design, fabrication and construction. Governments around the world are promoting BIM capacity to eliminate waste on public projects and even mandating its use as part of the reform of the public construction sector and cost saving strategy. In the United Kingdom, the government has declared that no public projects can be accepted without using BIM by 2016 (British Standard Institute [2]). Beside, the demands of clients in construction industry have also changed over years to meet with the wide spread development of society. There has been a growing urge for change from 'lowestprice wins' to 'multi-criteria selection' practices in supply chain selection process (Wong et al. [3]). Clients expect the best possible 'value' from SMEs because their expertise of work is usually supported by a continued high level of attention to all of their typical requirements (Mohamed and Egemen [4]). Thus, it is important that the construction organizations have to be well prepared to withstand the effects that may cause by spread adopting BIM for project delivery and the client requirements. In fact, the most vulnerable sectors of UK construction industry are SMEs which account for $99.9 \%$ of the 5.2 million private sector businesses and occupies 60\% (15.2 million) of UK private sector employment (Department for Business Innovation and Skills [5]). The amount of large companies adopting BIM are almost threefold more than smaller ones, the former making up 74\% in 2009 and this figure continuing to raise up to $91 \%$ in 2012 whereas BIM adoptions in Small firms are just around $25 \%$ in 2009 , followed by Small to Medium which account for 41\% (SmartMarket Report [6]). Blackwell [7] warns that SMEs who are slow in grasping and adopting BIM as a transformation technology and process could well lose contracts in both domestic and international market.

Currently, SMEs are lagging behind in BIM adoption and are losing out in wining publicly funded projects. The report from the Federation of Master Builders [8] presents that as many as 40 percent of construction SMEs lose out of 90 percent of the public sector work they proposed bids for, while more than half of SMEs claim to have identified a reduction in their rate of success in bidding for public sector contracts over the past five years. Hence, it is important to develop a decision support system (DSS) to help SMEs to identify and foresee potential risks and opportunities especially in the context of BIM reigning in project delivery. This DSS can help SMEs to make right decisions whether or not adopting BIM for project delivery in their organisations.

This paper will report on the framework and its criteria of an ongoing $\mathrm{PhD}$ research study undertaken to develop a DSS to anticipate risks and opportunities of adopting BIM in project delivery of SMEs. The outcome of the research will help SMEs to defeat their embarrassment, hesitation and vagueness of using BIM 
for conducting construction projects. It assists SMEs to make right decisions and to withstand growing changes of the construction industry in the UK especially after 2016.

\section{State of the arts}

It can be said that the UK construction industry seems strongly vibrant since the appearance of BIM, the term that experts in the industry so far have not got unique definitions to cover its huge effects on construction industry. BIM is defined as a revolutionary of technology (Hardin [9]); a process of generating and managing the digital representations of physical and functional characteristics of a building (Smith [10]); and a process of improving planning, designing, construction, operation and maintenance (Eastman et al. [11]).

BIM has changed traditional working in the construction industry by creating a new method of collaboration working based on digital model which can accommodate information on design, construction, logistics, operation, maintenance, budgets, and schedule during building lifecycle (HM Government [12]). By starting in very early stages of the project, designers are more likely to see the benefits of BIM as enhancing coordination, productivity, and business operations. Typically, they are likely to benefit from fundamental changes to the design process and the greater certainty between design intent and the final construction and operation of the building (Zuppa et al. [13]). BIM can be the significant approach to improve the interoperability within the supply chain including many different parties coming from different interests (Roger et al. [14]). The key factors of interoperability are effective communication, cooperation and integration between and among relevant departments in the organization to ensure that the tasks are well understood and implemented successfully. In other words, the management of design would not be isolated in the design department, but should involve the entire organisation, if commercially successful products are to be the outcome (Ughanwa [15]). Therefore, Roger et al. [14] point out that in business process characteristics for using BIM, the main efficiency are reducing costs, sharing information through interoperability and unlimited access leading to the integration of the various disciplines within the construction industry. In relation to procurement route, BIM is also acknowledged that it can be used for every procurement route and the level of benefits is varying according to the procurement characteristics. As such, BIM with an integrated model development will increase the collaboration, communication and decrease the unforeseen risks across large and complex projects (London and $\mathrm{Gu}[16]$ ).

The BIM agenda of the UK was initially driven by Tony Blair's New Labour Government who pushed forward the need to improve collaborative practices in construction. Sir John Egan was commissioned by the Government to produce a report "Rethinking Construction", which concluded "The movement would be a network through which members could collaborate with each other in developing construction techniques and skills and exchanging ideas for increasing efficiency and quality (Egan [17]). This report sought to change the industry towards collaboration, focusing on information with a view to increase efficiency. The 
Egan report aimed to drive efficiency in the UK construction industry, and this push to efficiency is reflected in the overall aim of reducing the cost of Government construction projects by $15-20 \%$ (Cabinet Office [18]). Along with the mandate of governments across the world in adopting BIM as part of the reform of the public construction sector and cost saving strategy, the UK government has also declared that no public projects can be accepted without using BIM by 2016 (British Standard Institute [2]). This mandate has strongly affected on the survival of a large number of small and medium-sized enterprises (SMEs) which generate about $80 \%$ of the production cost of the UK construction industry (Robson et al. [19]) because they will be lost to all business in the public sector after 2016 unless they adopt BIM into their organisations.

The recent report indicate that there are around two thirds of both public sector $(65 \%)$ and private sector $(70 \%)$ UK owner state that they will require BIM on their project compared to $30 \%$ of US public owners and just $11 \%$ of US private sector ones. However, the percentage of BIM users in the UK is at a low level of engagement and occupies the second highest rank which accounts for 54\%, whereas Brazil where the highest amount of low level of engagement investigated is 55\% (SmartMarket Report [20]). This indicates that the industry is still hesitating in using BIM for project delivery.

To support and encourage construction industry to adopt BIM for project delivery, there are many BIM group supports, standards and frameworks that have been developed so far:

- BIM Task Group is responsible for supporting and helping deliver the objectives of the UK Government's construction strategy and the requirement to strengthen the public sector's capability in BIM implementation with the aim that all central government departments will be adopting, as a minimum, collaborative Level 2 BIM by 2016 (BIM Tag Group [21]).

- BIM4SME is responsible for providing resource, best practices and knowledge to SMEs to get them ready for 2016 and embark on the construction industry's journey to deliver efficiencies in cost and value by sharing information (BIM4SME [22]).

- BIM Protocol created by Construction Institution Council in 2013 to clarify issues related to legal agreement including obligations and rights of stakeholders of BIM project (BIM Tag Group [21]).

- Public Available Specification (PAS) part 2, 3 and 4 developed specifically for information management for the capital/delivery phase of construction, operation phase of asset, and the exchange of information throughout the lifecycle of a facility (BIMTaggroup [21]).

Surprisingly, the report of SmartMartket Report 2014 points out that over three quarter $(76 \%)$ of UK respondents believe that they have well-developed BIM guidelines and none of them report being completely without guidelines (SmartMarket Report [20]). However, there have been no standards or frameworks developed to help SMEs to anticipate risks and opportunities of adopting BIM for project delivery. This may lead to embarrassing and hesitation among SMEs in adopting BIM for project delivery. In addition, the evidence shows that SMEs are 
currently lagging behind in BIM adoption (SmartMarket Report [20]) and are losing out in winning publicly funded projects - as many as $40 \%$ of construction SMEs lose out on $90 \%$ of the public sector work they proposed bids for (Federation of Master Builders [8]).

Therefore, it is significant to develop a framework to help SMEs to foresee opportunities and potential risks in BIM project delivery. To facilitate the wide spread use of this framework, it should be developed as a web-based tool so that it can be easy to publicise on the internet and disseminate to SMEs end users across the construction industry.

\section{The research methods used}

\subsection{Research stage 1: collect secondary data}

The data required for secondary research was collected from sources of existing information. This consists of relevant books, construction journals, online sources, international and local government reports. This progress is necessary to identify gaps of knowledge, key issues related to aim and objectives of the research. In addition, main criteria, sub-criteria and profile of risk and reward of adopting BIM in project delivery that SMEs are facing were also considered. Based on a literature review, the development of an appropriate conceptual framework for anticipating risk and opportunities of using BIM in project delivery was undertaken.

\subsection{Research stage 2: collect primary data}

The primary research data in this study will be achieved through a process of activities known as framework validation. Framework validation entails checking that the system complied with its own requirements and is free from failures or incorrect behaviour (Collofello [23]). This process is conducted by obtaining objective evidence that the system will perform its intended functions. The validation of a system is mostly a concern at the system level, and concentrates on whether or not the system can do what the user wants and is suitable for a specific intended use or application (Upadhyay [24]). Therefore, validation of the conceptual framework will help to ensure that the potential DSS will have full functionalities which will help SMEs to anticipate risks and rewards, and hence that the DSS works as intended. The following activities will present progress of validating the conceptual framework of the DSS:

- Activity 1: there will be several interviews including online chatting interview, face to face interview, phone interview have been being done to get more information supporting for the secondary data gained in stage 1 of the research.

- Activity 2: a combination of data collected from stage 1 and those achieved from activity 1 will be made to finalise the framework and its criteria. The criteria of framework as well as risk and opportunity profile may be amended and improved to fit with the context of the construction industry after this activity. 
- Activity 3: an online survey designed based on the outcome of activity 2 to collect data which will be used in functionalities of the DSS designed in next stage of the research.

\subsection{Research stage 3: design the DSS}

In this stage, the data after collecting in the second stage will be analysed and used to design the DSS. The online DSS tool will be designed by using the following packages of academic application:

- MySQL database management: used to store primary data after being analysed. This data is considered as the core data of the DSS tool, which is shown whenever end users choose functionalities of the DSS.

- $\quad$ The Hypertext Pre-processor (PhP): a programing language together with Hypertext Mark-up Language 5 (HTML5) and Cascading Style Sheet (CSS) will be adopted to design user interface and functions of the DSS tools.

The adoption of academic applications mentioned above is made because of following benefits:

- They are simple and easy to use.

- They have a large developer community that can extend their cooperation easily.

- They are open source content management programs. Therefore, the researcher does not need to pay for licences as well as issues related to the intellectual property when the DSS comes into operation.

\subsection{Research stage 4: validate the function and validity of the DSS}

In this stage of study, the completed DSS tool will be uploaded on a host website purchased by the researcher. The tool link will then be sent to SMEs (known as end users) across the UK construction industry for validating functionalities as well as its reliabilities. The end users will be asked to use the tool with a free account and investigate the usefulness and reliabilities of functionalities of the tool. In each function, they will be asked to put feedback about its convenience and the validities of information presented. All valuable feedback collected from participants in this stage will be used to improve the tool and will be compared with primary and secondary data in the discussion section of the research.

\section{Conceptual framework}

The aim of the study is to develop a DSS to help SMEs to assess the risks and rewards of adopting BIM for project delivery. Based on the existing literature, the conceptual framework of this research is designed to analyse in a holistic way the risks and rewards of BIM adoption in project delivery for SMEs. The framework will provide evidence regarding the benefits of BIM, to enable SMEs to foresee the significant advantages to be derived from BIM implementation and thus to encourage them to use BIM in their companies. It is hoped this will assist firms in meeting the UK government BIM adoption target for 2016-2020. The conceptual framework of the research can be seen in Figure 1. 


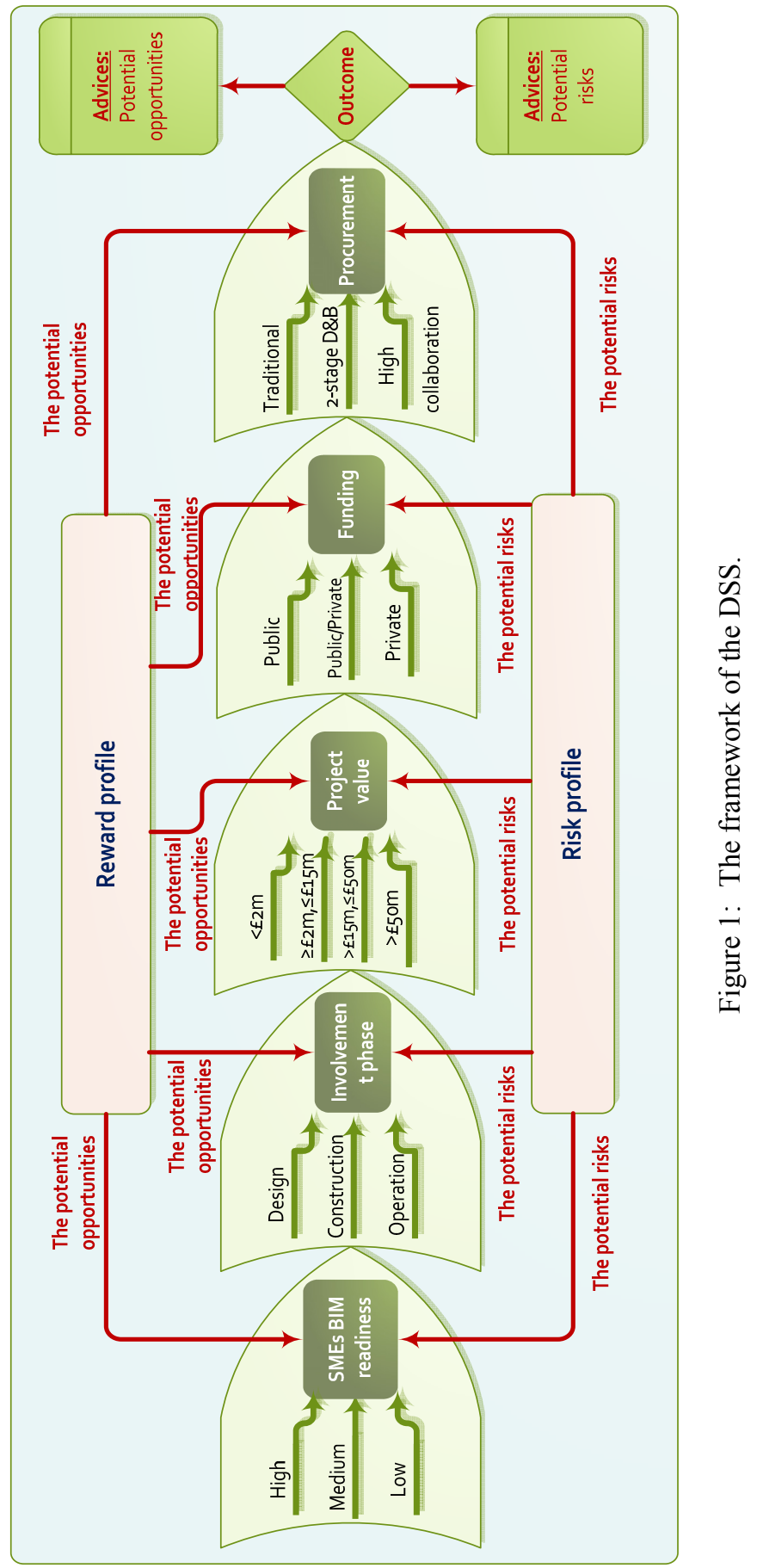




\section{Criteria of the framework}

The development of the conceptual framework has enabled the identification of key components, variables and their relationship, which may affect SMEs decision-making process regarding the use of BIM for specific project delivery. The conceptual framework mainly focuses on five key criteria that have a close relationship to the involvement of SMEs in project delivery. These are BIM readiness, involvement phase, project value, funding, and procurement route. In each criterion, there are three to four attributes (sub-criteria) which accommodate risks and rewards resulting from BIM adoption. All risks and rewards in all selected alternatives will be calculated and compared at the end of the process. Where the outcome demonstrates that the rewards dominate over risks during the process of project delivery, then adopting BIM in delivery construction project will be encouraged. In contrast, if the framework demonstrates that risks outweigh rewards or the rewards are insubstantial, then alternatives will be suggested. The criteria, sub-criteria and functionalities of DSS can be seen in Table 1.

Table 1: The criteria, sub-criteria and functionalities of DSS.

\begin{tabular}{|c|c|c|}
\hline Criteria & Sub-criteria & Comments (functionality of DSS) \\
\hline \multirow{3}{*}{$\begin{array}{l}\text { BIM } \\
\text { readiness }\end{array}$} & High & $\begin{array}{l}\text { The risks and opportunities that High BIM readiness } \\
\text { organisations may have when they participate in BIM projects } \\
\text { will be presented in this function. }\end{array}$ \\
\hline & Medium & $\begin{array}{l}\text { If an organisation is assumed as a Medium BIM readiness, } \\
\text { they can check their risks and opportunities of using BIM in } \\
\text { project delivery in this function. }\end{array}$ \\
\hline & Low & $\begin{array}{l}\text { Organisations with a BIM readiness considered as Low will be } \\
\text { the most interesting function that helps them to foresee risk } \\
\text { and opportunities of using BIM in project delivery. }\end{array}$ \\
\hline \multirow{3}{*}{$\begin{array}{l}\text { Stage of } \\
\text { involvement }\end{array}$} & Design & $\begin{array}{l}\text { This function will list all risks and opportunities that SMEs } \\
\text { involved in stages of design may have when they participate in } \\
\text { BIM projects. }\end{array}$ \\
\hline & Construction & $\begin{array}{l}\text { All SMEs participating in this stage of BIM projects, this } \\
\text { function can help them to foresee risks and opportunities that } \\
\text { they may face. }\end{array}$ \\
\hline & Operation & $\begin{array}{l}\text { As an organisation usually participates in latest stages of } \\
\text { project. This function will show them opportunities as well as } \\
\text { risks that they may scope in BIM projects. }\end{array}$ \\
\hline \multirow{4}{*}{ Project value } & Less than $£ 2 \mathrm{~m}$ & $\begin{array}{l}\text { This function may be useful for those SMEs that usually work } \\
\text { on small size projects. It helps SMEs to clarify either risks } \\
\text { dominated over opportunities or the opportunities. }\end{array}$ \\
\hline & $\begin{array}{l}\text { Between } £ 2 \mathrm{~m} \text { and } \\
£ 15 \mathrm{~m}\end{array}$ & \multirow{2}{*}{$\begin{array}{l}\text { To SMEs who usually work on this size of projects, these } \\
\text { functions can help them to check risks and opportunities that } \\
\text { BIM brings to them. The risks and opportunities presented in } \\
\text { these functions are meaningful in providing good evidence for } \\
\text { SMEs working in small and large size projects to look for a } \\
\text { comparison. }\end{array}$} \\
\hline & $\begin{array}{l}\text { Between } £ 15 \text { and } \\
£ 50 \mathrm{~m}\end{array}$ & \\
\hline & More than $£ 50 \mathrm{~m}$ & $\begin{array}{l}\text { Risks and opportunities of SME organisations working in large } \\
\text { size BIM projects shown in this function is hoped to be a } \\
\text { dream of by those SMEs working in lower size BIM projects. }\end{array}$ \\
\hline
\end{tabular}


Table 1: Continued.

\begin{tabular}{|c|c|c|}
\hline Criteria & Sub-criteria & \begin{tabular}{|c|} 
Comments (functionality of DSS) \\
\end{tabular} \\
\hline \multirow{4}{*}{ Project value } & Less than $£ 2 \mathrm{~m}$ & $\begin{array}{l}\text { This function may be useful for those SMEs that usually work } \\
\text { on small size projects. It helps SMEs to clarify either risks } \\
\text { dominated over opportunities or the opportunities. }\end{array}$ \\
\hline & $\begin{array}{l}\text { Between } £ 2 \mathrm{~m} \text { and } \\
£ 15 \mathrm{~m}\end{array}$ & $\begin{array}{l}\text { To SMEs who usually work on this size of projects, these } \\
\text { functions can help them to check risks and opportunities that }\end{array}$ \\
\hline & $\begin{array}{l}\text { Between } £ 15 \text { and } \\
£ 50 \mathrm{~m}\end{array}$ & $\begin{array}{l}\text { BIM brings to them. The risks and opportunities presented in } \\
\text { these functions are meaningful in providing good evidence for } \\
\text { SMEs working in small and large size projects to look for a } \\
\text { comparison. }\end{array}$ \\
\hline & More than $£ 50 \mathrm{~m}$ & $\begin{array}{l}\text { Risks and opportunities of SME organisations working in large } \\
\text { size BIM projects shown in this function is hoped to be a } \\
\text { dream of by those SMEs working in lower size BIM projects. }\end{array}$ \\
\hline \multirow{3}{*}{$\begin{array}{l}\text { Source of } \\
\text { funding }\end{array}$} & Public & $\begin{array}{l}\text { This function is to present risks and opportunities that SMEs } \\
\text { may have when they work in public funded BIM projects } \\
\text { especially after } 2016 \text {. }\end{array}$ \\
\hline & $\begin{array}{l}\text { Public/Private } \\
\text { (PPP, PFI, BOT, } \\
\text { etc.) }\end{array}$ & $\begin{array}{l}\text { Risks and opportunities presented in this function are deemed } \\
\text { to provide SMEs an overview of benefits that BIM brings to } \\
\text { this kind of project funding. }\end{array}$ \\
\hline & Private & $\begin{array}{l}\text { This function will show SMEs risks and opportunities that they } \\
\text { may have when they work in BIM projects funded by private } \\
\text { sectors. }\end{array}$ \\
\hline \multirow{3}{*}{$\begin{array}{l}\text { Procurement } \\
\text { route }\end{array}$} & $\begin{array}{l}\text { High collaborative } \\
\text { procurement }(\mathrm{e} . \mathrm{g} . \\
\text { Framework, } \\
\text { Partnering, IPD, ...) }\end{array}$ & $\begin{array}{l}\text { This function will be responsible for indicating potential } \\
\text { opportunities as well as risks that SMEs may have when they } \\
\text { work on BIM projects applied with high collaborative } \\
\text { procurement routes. }\end{array}$ \\
\hline & $\begin{array}{l}\text { Two-stage design } \\
\text { and build }\end{array}$ & $\begin{array}{l}\text { Risks and opportunities of using BIM in project delivery } \\
\text { applied two-stage D\&B procurement will be listed in this } \\
\text { function of the tool. }\end{array}$ \\
\hline & Traditional & $\begin{array}{l}\text { In delivering BIM project using traditional procurement route, } \\
\text { whether risks dominate over opportunities or not. This function } \\
\text { will help SMEs to anticipate them. }\end{array}$ \\
\hline $\begin{array}{l}\text { Profile of risk } \\
\text { and reward }\end{array}$ & \multicolumn{2}{|c|}{$\begin{array}{l}\text { The profile of risk and opportunity of the DSS was initially developed through } \\
\text { investigating literature during the stage } 1 \text { of the study. It then will be upgraded after } \\
\text { the progress of validating framework completed at the end of stage } 2 \text { of the research. } \\
\text { This profile is finally used to show users of the DSS risks and opportunities of } \\
\text { adopting BIM in project delivery according to specific functions that they choose. }\end{array}$} \\
\hline
\end{tabular}

\section{The DSS workflow and reporting}

The workflow diagram of the DSS (Figure 2), shows that there are a total of six steps that are used to anticipate risks and opportunities of using BIM in project delivery. Starting with identifying the BIM readiness of the assessors, the DSS then uses the involvement phase, the project value, the source of funding, and the procurement route as criteria to generate a final report at the end of the assessment process. The process of these steps is demonstrated by the solid lines in the diagram. The DSS also allows users to create interim reports at each step of the process. These reports include presenting risks and rewards at every typical 


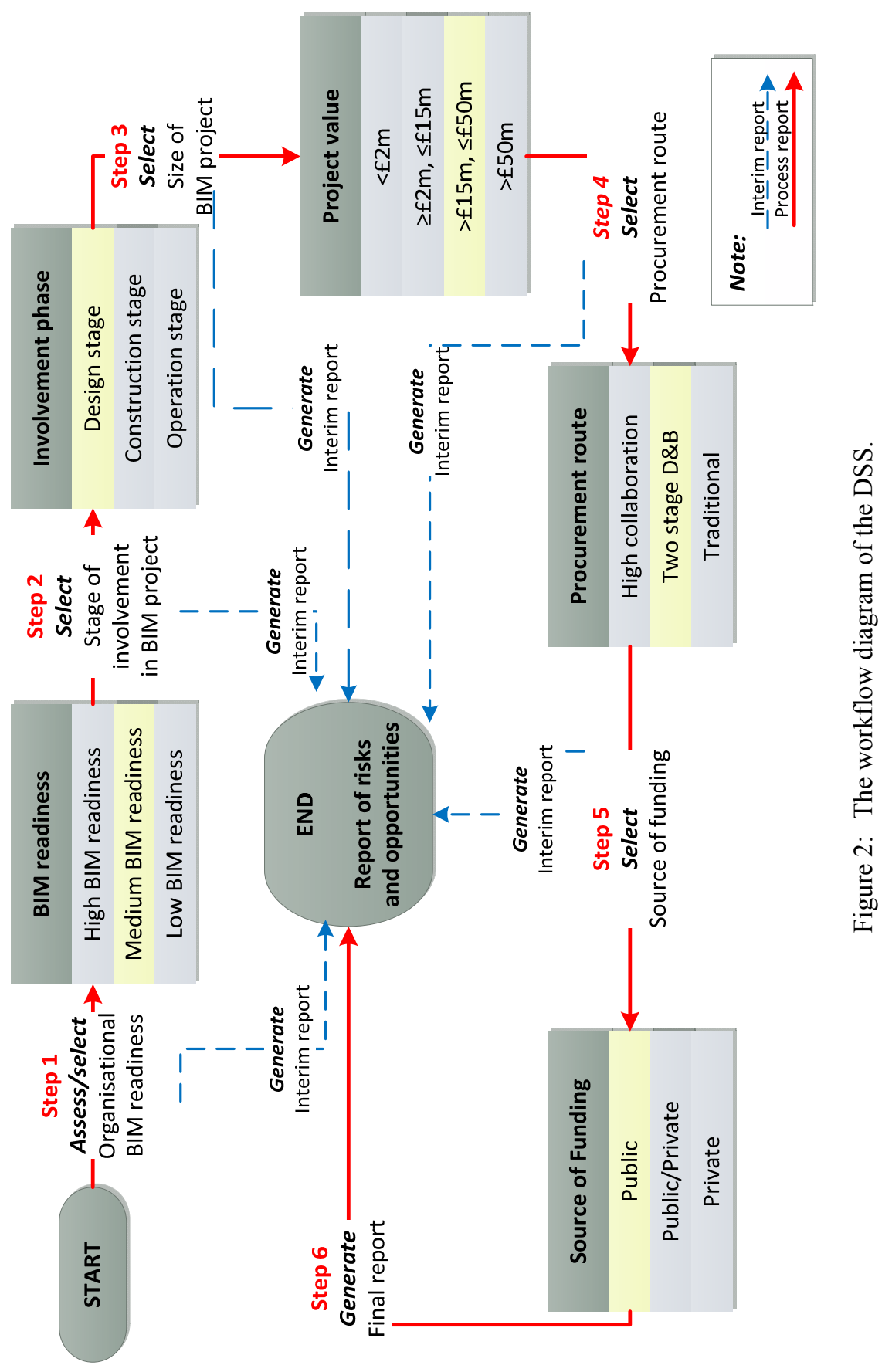


step of the process, and also showing total risks and opportunities that assessors have scoped, starting from the beginning, to the current step that the assessors are investigating (indicated by dash lines). This feature is designed to help organisations, which their businesses do not involve in all stages of assessment process, to anticipate risks and rewards of using BIM for project delivery. The typical steps of the assessment process are as follows:

- Workflow step 1: the users can choose directly their BIM readiness, or by doing self-assessment through answering a set of questions. Their answers will be used to assess their organisation's BIM readiness, which is high, medium or low. The interim report after this step can also show the risks and opportunities that their organisations may have.

- Workflow step 2: the assessors then can move on to select the stage of involvement in BIM projects, in order to foresee risks and opportunities. In this step, they can also generate the interim report to visualise risks and rewards that they have had so far. This report is created by combining the risks and rewards of this step, with the one that the assessors had in the previous step.

- Similarly, the next steps of the assessment process perform almost the same steps as the previous one. The assessors can respectively select options for each step, or choose a suitable selection which is close to the status of their organisation to generate the assessment report. Both interim and final report typically presents a list of risks and opportunities, as well as indicating the percentage of the risks and rewards sharing during the process of the assessment.

\section{Conclusion}

Since the 2011 mandate of the UK Government for BIM implementation level 2 on all public funded projects by 2016, the working style of the UK construction industry has changed rapidly from traditional to BIM in project delivery. The number of BIM users in the UK has recorded a strong increase in recent years especially in large size companies or those companies working in public sector. In contrast, this mandate also has increasingly affected SMEs where BIM has not been invested in. They are facing with losing all public projects and partly private contracts after 2016 due to the increasingly demand from both public and private clients. Typically, they are lagging behind and gradually losing in winning public projects in recent years. Although there are several researches, reports, frameworks, guidelines and standards have been conducted to assist SMEs in recognising the important benefits of BIM, there is still a lack of frameworks support for SMEs to forecast the outcome of using BIM in project delivery. To fulfil this gap, this research has been conducted and the DSS tool can help SMEs to anticipate risks and opportunities of adopting BIM for project delivery. It can also help SMEs to clarify advantages and disadvantages of using BIM according to their natural characteristics. The tool is hoped to help SMEs to deduce an 
appropriate decision making process in BIM investment and tangibly contribute to helping the UK Government to achieve their BIM target through encouraging SMEs to use BIM in project delivery.

\section{References}

[1] First step to BIM Competence, A Guide for Specialist Contractors. SEC Group - Website, http://www.secgroup.org.uk

[2] British Standard Institute. B/555 Roadmap (June 2013 Update) - Design, Construction \& Operational Data \& Process Management for the Built Environment. 2013.

[3] Wong, C, H., Holt G, D., Cooper, P, A., Lowest price or value? Investigation of UK construction clients' tender selection process. Construction Management and Economics. 18, pp. 767-774, 2000.

[4] Mohamed, A, N., Egemen, M., Clients' needs, wants and expectations from contractors and approach to the concept of repetitive works in the Northern Cyprus construction market. Building and Environment. 41, pp. 602-614, 2006.

[5] Department for Business Innovation and Skills - Statistical release. https://www.gov.uk/government/uploads/system/uploads/attachment_data/ file/377934/bpe 2014 statistical release.pdf

[6] SmartMarket Report. The Business Value of BIM in North America: MultiYear Trend Analysis and User Ratings (2007-2012). Bedford: McGrawHill Construction, 2012.

[7] Blackwell, B., Industrial strategy: Government and industry in partnership - Building Information Modelling. HM Government, 2012.

[8] Federation of Master Builders. Improving public procurement for construction SMEs. UK: Federation of Master Builders, 2013.

[9] Hardin, B., BIM and Construction Management, Indianapolis: Wiley Publishing, cited in Isikdag, U., Underwood, J. and Aouad, G. (2008) 'An investigation into the applicability of building information models in geospatial environment in support of site selection and fire response management processes', Advanced engineering informatics, 22, pp. 504519, 2009.

[10] Smith, D., An Introduction to Building Information Modeling (BIM). Journal of Building Information Modeling: 12-4, 2007.

[11] Eastman, C., Teicholz, P., Sack, R., Liston, K., BIM Handbook: A guide to Building Information Modeling for Owners, Managers, Designers, Engineers, and Contractors. $2^{\text {nd }} \mathrm{ed}$. The United States of America: John Wiley \& Son, Inc, 2011.

[12] HM Government. Digital Built Britain, Level 3 Building Information Modelling - Strategic Plan. February 2015.

[13] Zuppa, D., Raja R., Issa A., Suermann P,C., BIM's impact on the success measures of construction projects, Computing in Civil Engineering, pp. 503512, 2009. 
[14] Roger, W., Alshawi, M., Hore, A., Redmond, A., Exploring how information exchanges can be enhanced through Cloud BIM. Automation in Construction. 24, pp. 175-183, 2012.

[15] Ughanwa, D, O., Better ways of managing design: the Queen's Award winners' experience. Technoation 7, pp. 337-399, 1988.

[16] London, K., Gu, N., Understanding and facilitating BIM adoption in the AEC industry. Journal of Automation in Construction 19, pp. 988-999, 2010.

[17] Egan, J., Rethinking Construction. Report of the Construction Task Force. London: HMSO, 1998.

[18] Cabinet Office. Government Construction Strategy. One year on report and action plan update. London: The Stationery Office, 2012.

[19] Robson, A., Boyd, D., Thurairajah, N., UK Construction Supply Chain Attitudes to BIM. 50 ${ }^{\text {th }}$ ASC Annual International Conference Proceeding. Birmingham, UK, 2014.

[20] SmartMarket Report. The Business Value of BIM for Construction in Major Global Markets: How Contractors Around the World Are Driving Innovation With Building Information Modelling. Bedford: McGraw-Hill Construction, 2014.

[21] Building Information Modelling (BIM) Tag Group, www.BIMTaggroup.org

[22] Building Information Modelling for Small and Medium-sized Enterprises organisation (BIM4SME), http://www.bim4sme.org/education/\#faqs

[23] Collofello, J, S., Introduction to Software Verification and Validation. The US Department of Defense, 1998.

[24] Upadhyay, P., The roles of Verification and Validation in System Development Life Cycle. IOSR Journal of Computer Engineering. 5(1), pp. 17-20, 2012. 